\title{
Hyperfractionated or Accelerated Hyperfractionated Re-irradiation with $\geq 42$ Gy in Combination with Paclitaxel for Secondary/Recurrent Head-and-Neck Cancer
}

\author{
DIRK RADES ${ }^{1}$, TOBIAS BARTSCHT ${ }^{2}$, CHRISTIAN IDEL $^{1,3}$, STEVEN E. SCHILD $^{4}$ and SAMER G. HAKIM ${ }^{5}$ \\ Departments of ${ }^{1}$ Radiation Oncology, ${ }^{2}$ Hematology and Medical Oncology, \\ ${ }^{3}$ Oto-Rhino-Laryngology and Head and Neck Surgery and ${ }^{5}$ Oral and Maxillofacial Surgery, \\ University of Lübeck, Lübeck, Germany; \\ ${ }^{4}$ Department of Radiation Oncology, Mayo Clinic, Scottsdale, AZ, U.S.A.
}

\begin{abstract}
Background/Aim: Patients with secondary/ recurrent squamous cell head and neck cancer (SCCHN) have poor prognoses. Outcomes of re-irradiation with $\geq 42$ Gy plus paclitaxel for secondary/recurrent SCCHN are herein presented. Patients and Methods: Two patients reirradiated for secondary/recurrent SCCHN were evaluated. Patients received $44.4 \mathrm{~Gy}(2 \times 1.2 \mathrm{~Gy} /$ day $)$ or $42.0 \mathrm{~Gy}(2 \times 1.5$ Gy/day), respectively, plus concurrent paclitaxel $\left(35 \mathrm{mg} / \mathrm{m}^{2}\right.$ weekly or $20 \mathrm{mg} / \mathrm{m}^{2}$ twice per week). Results: One patient developed a locoregional recurrence and additional metastases at 12 months after re-irradiation and died at 13 months. The other patient developed multiple bone metastases at 103 months and died at 104 months. Acute toxicities included grade 2 anemia and mucositis in both patients. Radiation dermatitis was grade 2 in one patient and grade 3 in the other. Conclusion: Reirradiation with 42.0-44.4 Gy given twice daily plus paclitaxel was well tolerated and achieved a favorable response. The results need to be confirmed in a prospective trial.
\end{abstract}

Many patients with locally advanced squamous cell carcinoma of the head and neck (SCCHN) receive radiotherapy or chemoradiation, either as a definitive approach or following surgery (1-6). Depending on the situation (no surgery, complete resection, microscopically or macroscopically incomplete resection), total radiation doses

This article is freely accessible online.

Correspondence to: Professor Dirk Rades, MD, Department of Radiation Oncology, University of Lübeck, Ratzeburger Allee 160, 23538 Lübeck, Germany. Tel: +49 4515006661, Fax: +49 4515003324, e-mail: rades.dirk@gmx.net

Key Words: Secondary/recurrent head-and-neck cancer, reirradiation, hyperfractionation, acceleration, concurrent paclitaxel. mostly range between 60 and 70 Gy $(7,8)$. When patients irradiated with these high doses develop a locoregional recurrence of SCCHN or a secondary SCCHN, they again would require doses of 60-70 Gy as definitive or postoperative treatment to achieve optimal tumor control. However, re-irradiation (second course of radiotherapy in the same region) with such a high dose is generally risky, because the cumulative dose of the first and the second courses of radiotherapy is above the tolerance doses of the surrounding normal tissues and organs (9). Therefore, lower doses are often administered for re-irradiation. Whenever possible, re-irradiation should be accompanied by concurrent chemotherapy because of findings from a randomized trial of 384 patients with SCCHN demonstrated that the addition of concurrent chemotherapy resulted in significantly better local control, and progression-free and overall survival when compared to escalation of the radiation dose by $10 \%$ (10). Another important variable of re-irradiation is the dosefractionation regimen. Giving doses per fraction of less than $1.8 \mathrm{~Gy}$, twice daily, can reduce the risk of late toxicities because in contrast to tumor cells, normal tissues are able to recover within 6-8 hours following irradiation (11). Thus, reirradiation of SCCHN should ideally include radiotherapy with two daily fractions of less than $1.8 \mathrm{~Gy}$ and concurrent chemotherapy. Many patients with SCCHN requiring a second course of radiotherapy cannot receive platin-based chemotherapy, which is the most common chemotherapy approach for SCCHN, because of significant potential toxicities, particularly those patients who had previously received platin-based chemotherapy (12). The most appropriate alternative single-agent or combination chemotherapy should take into account the patient's age, performance status and co-morbidities. For selected patients, taxane monotherapy is a reasonable option shown to be effective for SCCHN (13-17). In two previous studies of reirradiation of recurrent SCCHN, we combined paclitaxel 
Table I. Patient characteristics and results of treatment for secondary/recurrent tumors.

\begin{tabular}{lcc}
\hline Characteristic & Patient 1 & Patient 2 \\
\hline Age at the time of the primary tumor & 56 Years & 37 Years \\
Site of primary tumor & Base of tongue & Larynx + hypopharynx \\
Treatment of primary tumor & Complete resection +66 Gy & Complete resection +60 Gy \\
Interval between both courses of radiotherapy & 111 Months & 311 Months \\
Site of secondary/recurrent tumor & Hypopharynx & Oropharynx + hypopharynx \\
Stage of secondary/recurrent tumor & T4 N3 M1 (LYM, OSS) & T4 N0 M0 \\
Age at the time of secondary/recurrent tumor & 67 years & 63 years \\
Treatment of secondary/recurrent tumor prior to re-irradiation & Complete resection & Macroscopicacally incomplete resection \\
& $(1$ year earlier) & $(1$ month earlier) \\
Total dose of re-irradiation & 42.0 Gy & 44.4 Gy \\
Fractionation of re-irradiation & $2 \times 1.5 \mathrm{~Gy}$ per day & $2 \times 1.2 \mathrm{~Gy}$ per day \\
& on 5 days per week & on 5 days per week \\
Concurrent paclitaxel & $35 \mathrm{mg} / \mathrm{m}^{2}$ weekly & 20 mg/m 2 twice per week \\
Locoregional recurrence & None & None \\
Distant metastasis & At 12 months & At 103 months \\
Death & At 13 months & At 104 months \\
\hline
\end{tabular}

with either 30 or 36 Gy (1.5 Gy twice daily) of radiotherapy $(16,17)$. However, 36 Gy may be too low to achieve longterm disease control. Therefore, in the present study, the total dose of re-irradiation was further escalated to $\geq 42 \mathrm{~Gy}$.

\section{Patients and Methods}

From our database of more than 750 patients irradiated for SCCHN, two were identified who had received a second course of radiotherapy with a total dose of $>40$ Gy in combination with concurrent paclitaxel for a secondary/recurrent SCCHN.

In patients receiving definitive radiotherapy for SCCHN, radiation oncologists aim to keep the overall treatment time short to improve outcomes. This can be achieved with hyperfractionated radiotherapy (e.g. $2 \times 1.2$ Gy per day on 5 days per week) or acceleratedhyperfractionated radiotherapy (e.g. $2 \times 1.5$ Gy per day on 5 days per week) instead of conventionally fractionated radiotherapy $(1 \times 1.8 \mathrm{~Gy}$ or $1 \times 2.0$ Gy per day on 5 days per week). In the present study, one patient received re-irradiation with 44.4 Gy $(2 \times 1.2$ Gy per day) for a locoregional recurrence plus a metastasis in the sternum 1 year after complete resection of a secondary SCCHN and 9.5 years following his first SCCHN treated with resection plus $66 \mathrm{~Gy}$. The other patient received postoperative radiotherapy with $42.0 \mathrm{~Gy}$ ( $2 \times 1.5$ Gy per day) one month after macroscopically incomplete resection of the secondary/recurrent SCCHN and 26 years following resection plus $60 \mathrm{~Gy}$ for his first SCCHN.

The biological effective doses for tumor cell kill given by the equivalent dose in 2-Gy fractions were 45.9 Gy and $45.5 \mathrm{~Gy}$, respectively. The EQD2s with respect to late radiation-related toxicity were $37.3 \mathrm{~Gy}$ and $37.8 \mathrm{~Gy}$, respectively. Since both fractionation regimens were similarly effective, both patients were included in this study. Re-irradiation was performed in 2008 and 2010 , respectively, with 3D-conformal radiotherapy following computed tomography-based treatment planning. Both patients received concurrent paclitaxel $\left(35 \mathrm{mg} / \mathrm{m}^{2}\right.$ weekly and $20 \mathrm{mg} / \mathrm{m}^{2}$ twice per week, respectively). Prior to each application of paclitaxel, the patients received intravenously administration of 2 mg clemastine, $1 \mathrm{mg}$ granisetron and $8 \mathrm{mg}$ dexamethasone. Patient characteristics are shown in Table I.

Investigated endpoints included acute toxicity and treatment outcomes in terms of locoregional control, metastasis and death. Treatment outcomes were referenced from the day of presentation to a radiation oncologist for re-irradiation. The assessment of acute toxicities was performed according to the Common Terminology Criteria of Adverse Events (CTCAE) version 4.0 (18).

\section{Results}

One patient already had mediastinal lymph node metastases and bone metastasis in the sternum at the time of the secondary SCCHN. He developed both a locoregional recurrence and additional metastases at 12 months and died at 13 months after presentation for re-irradiation of the secondary SCCHN. The other patient had not developed locoregional recurrence during the period of follow-up but developed multiple bone metastases at 103 months and died at 104 months after presentation for re-irradiation. Treatment results are included in Table I. Acute toxicities included grade 2 anemia and grade 2 oral mucositis in both patients. Radiation dermatitis was grade 2 and grade 3 , respectively. Both patients received the treatment for the secondary SCCHN as planned.

\section{Discussion}

Many patients with SCCHN who experience locoregional recurrence or a secondary $\mathrm{SCCHN}$ receive a second course of irradiation combined with concurrent chemotherapy (16, 
17, 20). Taking into account the tolerance doses of the organs at risk and the fact that such patients had already received total doses of 60-70 Gy as part of the treatment of the primary SCCHN, it is not particularly safe to deliver a second course of radiotherapy with 60 Gy or higher doses (11). The risk of late toxicities can potentially be reduced, if doses per fraction of less than $1.8 \mathrm{~Gy}$ are given twice daily with an interval of 6-8 hours between the two daily fractions (11). This approach gives the cells of the organs at risk time to recover from the previous radiation fraction. In contrast, tumor cells are far less able to recover between two fractions. The effect of radiotherapy on SCCHN can be increased probably by at least $15 \%$ with the addition of concurrent radiosensitizing chemotherapy (10). In two very small retrospective studies, we combined 30 Gy and 36 Gy (1.5 Gy per fraction given twice daily), respectively, with paclitaxel $(16,17)$. In both studies, this approach appeared effective and quite feasible. However, the total doses given as EQD2 were 32.5 Gy and 39.0 Gy, respectively. Adding $15 \%$ for concurrent chemotherapy would mean that the biological effect of the treatment may be considered comparable to doses of $37.4 \mathrm{~Gy}$ and $44.9 \mathrm{~Gy}$, respectively, which are still well below 60 Gy $(10,11)$. Therefore, we investigated a further escalation of the radiation dose. The EQD2 of the two regimens used in this study were $45.5 \mathrm{~Gy}$ and $45.9 \mathrm{~Gy}$, respectively. After adding 15\% for concurrent chemotherapy, the doses may be considered comparable to $52.3 \mathrm{~Gy}$ and $52.8 \mathrm{~Gy}$, respectively, which are closer to $60 \mathrm{~Gy}$ and are likely minimally required to eradicate local disease. Given the advanced stage at the time of re-irradiation, both our patients benefited from the treatment in terms of local control and overall survival. Moreover, the treatment with escalated dose of re-irradiation plus concurrent paclitaxel appeared feasible. Hematotoxicity and oral mucositis did not exceed grade 2 , and grade 3 dermatitis, which occurred in one patient, was managed without problems. Both patients received the entire treatment as planned. The outcomes in terms of overall survival and locoregional control in the present study appeared quite favorable, particularly when compared to the outcomes of previous studies in patients with recurrent SCCHN using modern radiation techniques (21-26). The 1year overall survival rates in the previous studies ranged from $33 \%$ to $77 \%$, and the 1-year locoregional control rates ranged between $44 \%$ and $80 \%$ (21-26). Regarding acute toxicities, one patient in the present study developed grade 3 radiation dermatitis. In our two previous studies, acute toxicities did not exceed grade $2(16,17)$. In other studies, grade 3 or more toxicities were observed in up to $36 \%$ of patients, and even treatment-related death occurred in up to $12 \%$ of the patients (21-26). In order to properly judge the feasibility and the efficacy of re-irradiation with doses $\geq 42.0$ Gy plus paclitaxel, a prospective phase I trial is required, followed by a randomized phase II or phase III trial.
In conclusion, re-irradiation with 42.0-44.4 Gy (1.2-1.5 Gy per fraction twice daily) plus paclitaxel led to favorable results in these two patients. However, given the retrospective study design and the very limited number of patients, the results are anecdotal and need to be confirmed in a prospective trial before this regimen can be introduced into clinical routine.

\section{Conflicts of Interest}

On behalf of all Authors, the corresponding Author states that there is no conflict of interest related to this study.

\section{References}

1 Lefebvre JL, Rolland F, Tesselaar M, Bardet E, Leemans CR, Geoffrois L, Hupperets P, Barzan L, de Raucourt D, Chevalier D, Licitra L, Lunghi F, Stupp R, Lacombe D, Bogaerts J, Horiot JC, Bernier $\mathrm{J}$ and Vermorken JB; EORTC Head and Neck Cancer Cooperative Group; EORTC Radiation Oncology Group: Phase 3 randomized trial on larynx preservation comparing sequential $v s$. alternating chemotherapy and radiotherapy. J Natl Cancer Inst 101: 142-152, 2009.

2 Rades D, Stoehr M, Meyners T, Bohlen G, Nadrowitz R, Dunst J, Schild SE, Wroblewski J, Albers D, Schmidt R, Alberti W and Tribius S: Evaluation of prognostic factors and two radiation techniques in patients treated with surgery followed by radio (chemo)therapy or definitive radio(chemo)therapy for locally advanced head-and-neck cancer. Strahlenther Onkol 184: 198-205, 2008.

3 Seidl D, Janssen S, Strojan P, Bajrovic A, Schild SE and Rades D: Prognostic factors after definitive radio(chemo)therapy of locally advanced head and neck cancer. Anticancer Res 36: 2523-2526, 2016.

4 Rades D, Kronemann S, Meyners T, Bohlen G, Tribius S, Kazic N, Schroeder U, Hakim SG, Schild SE and Dunst J: Comparison of four cisplatin-based radiochemotherapy regimens for nonmetastatic stage III/IV squamous cell carcinoma of the head and neck. Int J Radiat Oncol Biol Phys 80: 1037-1044, 2011.

5 Rades D, Meyners T, Kazic N, Bajrovic A, Rudat V and Schild SE: Comparison of radiochemotherapy alone to surgery plus radio(chemo)therapy for non-metastatic stage III/IV squamous cell carcinoma of the head and neck: A matched-pair analysis. Strahlenther Onkol 187: 541-547, 2011.

6 Rades D, Seidl D, Janssen S, Bajrovic A, Hakim SG, Wollenberg B, Karner K, Strojan P and Schild SE: Chemoradiation of locally advanced squamous cell carcinoma of the head-and-neck (LASCCHN): Is $20 \mathrm{mg} / \mathrm{m}$ (2) cisplatin on five days every four weeks an alternative to $100 \mathrm{mg} / \mathrm{m}(2)$ cisplatin every three weeks? Oral Oncol 59: 67-72, 2016.

7 Seidl D, Janssen S, Strojan P, Hakim SG, Wollenberg B, Schild SE and Rades D: Importance of chemotherapy and radiation dose after microscopically incomplete resection of stage III/IV head and neck cancer. Anticancer Res 36: 24872491, 2016.

8 Rades D, Janssen S, Bajrovic A, Strojan P and Schild SE: A total radiation dose of $70 \mathrm{~Gy}$ is required after macroscopically incomplete resection of squamous cell carcinoma of the head and neck. Anticancer Res 36: 2989-2992, 2016. 
9 Marks LB, Yorke ED, Jackson A, Ten Haken RK, Constine LS, Eisbruch A, Bentzen SM, Nam J and Deasy JO: Use of normal tissue complication probability models in the clinic. Int $\mathrm{J}$ Radiat Oncol Biol Phys 76(3 Suppl): S10-19, 2010.

10 Budach V, Stuschke M, Budach W, Baumann M, Geismar D, Grabenbauer G, Lammert I, Jahnke K, Stueben G, Herrmann T, Bamberg M, Wust P, Hinkelbein W and Wernecke KD: Hyperfractionated accelerated chemoradiation with concurrent fluorouracil-mitomycin is more effective than dose-escalated hyperfractionated accelerated radiation therapy alone in locally advanced head and neck cancer: final results of the radiotherapy cooperative clinical trials group of the German Cancer Society 95-06 Prospective Randomized Trial. J Clin Oncol 23: 1125$1135,2005$.

11 Joiner MC and Van der Kogel AJ: The linear-quadratic approach to fractionation and calculation of isoeffect relationships. In: Steel GG (ed.): Basic Clinical Radiobiology. New York, Oxford University Press, pp. 106-112, 1997.

12 De Castro G Jr, Snitcovsky IM, Gebrim EM, Leitão GM, Nadalin W, Ferraz AR and Federico MH: High-dose cisplatin concurrent to conventionally delivered radiotherapy is associated with unacceptable toxicity in unresectable, non-metastatic stage IV head and neck squamous cell carcinoma. Eur Arch Otorhinolaryngol 264: 1475-1482, 2007.

13 Lövey J, Koronczay K, Remenár E, Csuka O and Németh G: Radiotherapy and concurrent low-dose paclitaxel in locally advanced head and neck cancer. Radiother Oncol 68: 171-174, 2003.

14 Citrin D, Mansueti J, Likhacheva A, Sciuto L, Albert PS, Rudy SF, Cooley-Zgela T, Cotrim A, Solomon B, Colevas AD, Russo A, Morris JC, Herscher L, Smith S and Van Waes C: Long-term outcomes and toxicity of concurrent paclitaxel and radiotherapy for locally advanced head-and-neck cancer. Int J Radiat Oncol Biol Phys 74: 1040-1046, 2009.

15 Halim AA, Wahba HA, El-Hadaad HA and Abo-Elyazeed A: Concomitant chemoradiotherapy using low-dose weekly gemcitabine versus low-dose weekly paclitaxel in locally advanced head and neck squamous cell carcinoma: a phase III study. Med Oncol 29: 279-284, 2012.

16 Rades D, Seidl D, Wollenberg B, Schild SE and Hakim SG: Radiochemotherapy with paclitaxel for recurrent previously irradiated squamous cell carcinoma of the head and neck. Anticancer Res 36: 5463-5468, 2016.

17 Rades D, Bartscht T, Idel C and Hakim SG: Re-irradiation with 36 Gy (1.5 Gy twice daily) plus paclitaxel for advanced recurrent and previously irradiated SCCHN is feasible. Anticancer Res 38: 519-523, 2018.
18 Kaplan EL and Meier P: Non parametric estimation from incomplete observations. J Am Stat Assoc 53: 457-481, 1958.

19 National Institutes of Health/National Cancer Institute: Common Terminology Criteria for Adverse Events (CTCAE) version 4.0. National Institutes of Health/National Cancer Institute, 2009.

20 Seidl D, Schild SE, Wollenberg B, Hakim SG and Rades D: Prognostic factors in patients irradiated for recurrent head-andneck cancer. Anticancer Res 36: 6547-6550, 2016.

21 Cvek J, Knybel L, Skacelikova E, Stransky J, Matousek P, Zelenik K, Res O, Otahal B, Molenda L and Feltl D: Hyperfractionated stereotactic reirradiation for recurrent head and neck cancer. Strahlenther Onkol 192: 40-46, 2016.

22 Dornoff N, Weiß C, Rödel F, Wagenblast J, Ghanaati S, Atefeh N, Rödel $\mathrm{C}$ and Balermpas P: Re-irradiation with cetuximab or cisplatin-based chemotherapy for recurrent squamous cell carcinoma of the head and neck. Strahlenther Onkol 191: 656-664, 2015.

23 Hayashi Y, Nakamura T, Mitsudo K, Kimura K, Yamaguchi H, Ono T, Azami Y, Takayama K, Hirose K, Yabuuchi T, Suzuki M, Hatayama Y, Kikuchi Y, Wada H, Fuwa N, Hareyama M and Tohnai I: Re-irradiation using proton beam therapy combined with weekly intra-arterial chemotherapy for recurrent oral cancer. Asia Pac J Clin Oncol 13: e394-e401, 2017.

24 Jeong S, Yoo EJ, Kim JY, Han CW, Kim KJ and Kay CS: Reirradiation of unresectable recurrent head and neck cancer: using helical tomotherapy as image-guided intensity-modulated radiotherapy. Radiat Oncol J 31: 206-215, 2013.

25 Al-Wassia R, Vakilian S, Holly C, Sultanem K and Shenouda G: A retrospective study of head and neck re-irradiation for patients with recurrent or second primary head and neck cancer: the McGill University experience. J Otolaryngol Head Neck Surg 44: 31, 2015.

26 Yamazaki H, Demizu Y, Okimoto T, Ogita M, Himei K, Nakamura S, Suzuki G, Yoshida K, Kotsuma T and Yoshioka Y: Comparison of re-irradiation outcomes for charged particle radiotherapy and robotic stereotactic radiotherapy using CyberKnife for recurrent head and neck cancers: A multi-institutional matched-cohort analysis. Anticancer Res 36: 5507-5514, 2016.

Received April 3, 2018

Revised May 4, 2018

Accepted May 9, 2018 